\title{
Low Surface Recombination in Silicon Heterojunction Solar Cells with Rear Laser-Fired Contacts from Aluminum Foils
}

\author{
M. Colina, A. Morales-Vilches, C. Voz, I. Martín, P. Ortega and R. Alcubilla \\ The authors are with Universitat Politecnica de Catalunya, Departament d'Enginyeria Electronica, Grup de Recerca en Micro i Nanotecnologies. \\ c/ Jordi Girona 1-3, Campus Nord, 08034 Barcelona, Spain. Tel: +3493 4017488, e-mail: cristobal.voz@upc.edu.
}

\begin{abstract}
In this work an approach to create laser-fired contacts from aluminum foils is studied on p-type silicon heterojunction solar cells. This alternative approach consists in the use of aluminum foils instead of evaporated layers as a metal source and rear electrode for the laser-firing process. A q-switched infrared laser $(1064 \mathrm{~nm})$ was employed to create the local point contacts. Quasi-Steady-State Photoconductance measurements evidenced a limited degradation in the surface passivation quality during the laser-firing process. Heterojunction solar cells fabricated with these rear contacts reached a best conversion efficiency of $18 \%$ with a remarkable opencircuit voltage of $690 \mathrm{mV}$. These values were very close to those of reference devices fabricated with evaporated aluminum layers. This result suggests a similar effect on the rear surface passivation by both contact strategies. However, external quantum efficiency curves revealed a better response of devices with a rear aluminum foil in the near infrared. Optical measurements indicate that this effect can be related to a higher internal reflection at the back surface. Consequently, laser-fired contacts from aluminum foils appear as a fast and convenient solution for the rear contact of high-efficiency silicon solar cells.

Index Terms- Amorphous silicon, crystalline silicon, heterojunctions, solar cells, laser-fired contacts, surface passivation.
\end{abstract}

\section{INTRODUCTION}

Silicon heterojunction (SHJ) solar cell technology has been extensively developed during the past two decades [1]. A record conversion efficiency of $24.7 \%$ was recently reported for a solar cell with double heterojunction structure based on a thin n-type crystalline $\mathrm{Si}$ (c-Si) wafer [2]. Nevertheless, very few details about the fabrication process have been revealed by the most successful manufacturer of SHJ solar cells, Panasonic (formerly Sanyo). Fundamentally, n-type c-Si substrates could be preferred for SHJ solar cells attending to the reported asymmetry in the conduction and valence band offsets with hydrogenated amorphous silicon [3][4]. In any case, conversion efficiencies above 21\% have also been demonstrated in SHJ solar cells based on p-type wafers [4]. This type of substrates is more widely-used in the photovoltaic industry for the fabrication of conventional solar cells with diffused emitter. This fact makes research on p-type c-Si also attractive for the development of a technology readily extensible to the industry. An advantage of p-type wafers is the possibility to use diffused aluminum (Al) point contacts at the rear side in combination with a dielectric passivation layer, as in the passivated emitter and rear cell (PERC) concept [5]. Such a solar cell structure presents technological advantages, since the p-doping gas can be eliminated from the fabrication process. This advantage is especially relevant for amorphous silicon deposition systems with only one vacuum chamber. In industrial-PERC (i-PERC) solar cells a laser is used for opening the dielectric, while point contacts are formed later from an $\mathrm{Al}$ paste in a high-temperature co-firing step [6]. An alternative approach compatible with low-temperature processing is the laserfiring technique, where point contacts are formed directly during the laser step [7][8]. The laser-firing technique has excelled in the last years owing to its high potential and flexibility [9]. To date, different kinds of lasers [10] and alternative metallic sources [11][12] have been successfully tested to produce laser-fired contacts (LFC) in complete solar cells. Conversion efficiencies over $20 \%$ [13][14] were reported for a conventional diffused emitter, whereas in low-temperature heterojunction devices we have recently obtained efficiencies around $18 \%$ [15].

In this work, the influence of the laser-firing process on the SHJ solar cell performance is studied in detail. In particular, the effect on the rear surface recombination is analyzed for two different cases. First, conventional laser-fired contacts obtained from an $\mathrm{Al}$ layer evaporated in vacuum. Second, an alternative process where commercially available aluminum foils are attached directly to the solar cell structure during the laser-firing process [16]. This strategy does not require any vacuum deposition or annealing step, which results in a cost reduction that could promote the laser-firing technique into the PV industry. The high potential of this approach has been demonstrated previously on a rear passivation stack of alumina and silicon oxide for conventionally diffused-emitter c-Si solar cells [12]. In this work the heterojunction emitter and a rear passivation structure based on amorphous silicon, along with the introduction of $\mathrm{Al}$ foil rear electrodes, lead to a simplified low-temperature fabrication process for high-efficiency silicon solar cells. Our results indicate that this alternative method is able to maintain a high passivation quality, while a beneficial enhancement of the back reflection of infrared radiation could be simultaneously observed.

This work has been supported by the Spanish Ministry of Science and Innovation under projects ENE2013-48629-C4-1-R and TEC2011-26329 and by the European Comission (FP7, project HERCULES) under Grant agreement 60898. 


\section{II.EXPERIMENTAL}

\section{A. Test samples and Solar Cells}

The test samples and complete solar cells studied in this work were prepared on p-type $(0.5 \Omega \cdot \mathrm{cm}$ and $2.5 \Omega \cdot \mathrm{cm}) 4$ inch FZ c-Si wafers of thickness $280 \mu \mathrm{m}$ with $\langle 100\rangle$ crystalline orientation. Figure 1 shows the structure of the test samples used to study the surface passivation losses caused during the laser-firing process. The c-Si wafers were passivated by a stack of two hydrogenated amorphous silicon-carbide $\left(\mathrm{a}-\mathrm{SiC}_{\mathrm{x}}: \mathrm{H}\right)$ layers with different carbon contents: $\mathrm{x} \approx 0.2$ in the $\mathrm{Si}$-rich $30 \mathrm{~nm}$ thick passivation layer (PAS), and $\mathrm{x} \approx 1$ in the almost stoichiometric $70 \mathrm{~nm}$ thick antireflection layer (ARC) of refractive index $\mathrm{n} \approx 2$. All these layers were deposited at a substrate temperature of $300{ }^{\circ} \mathrm{C}$ in a direct PECVD system (13.56 MHz) from Elettrorava S.p.A. A complete description of the deposition conditions used to obtain these films was included in a previous work [15].

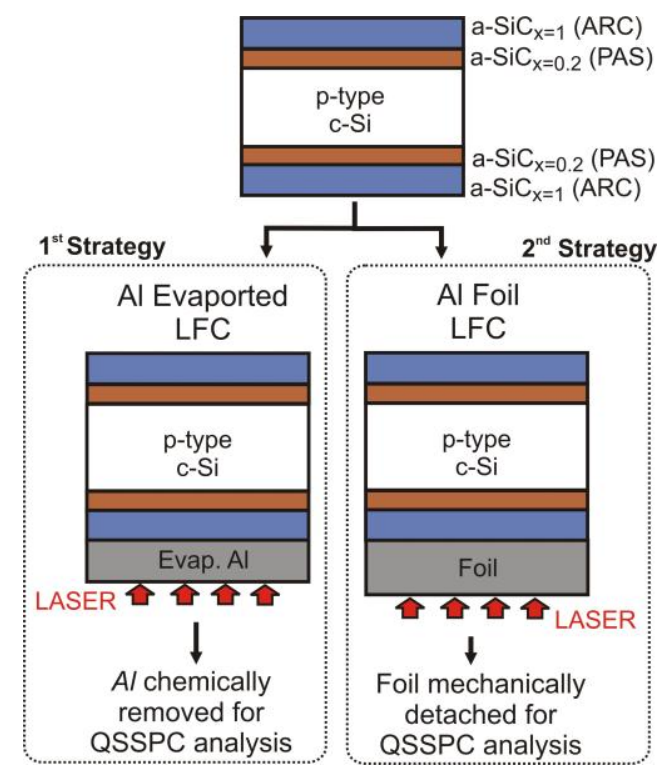

Fig. 1. Diagram of the test sample structures used to study the passivation losses caused during the laser-firing process. The two different approaches for applying the aluminum rear metallization are also distinguished in this diagram.

Concerning the fabrication of complete silicon heterojunction solar cells (Fig. 2), a random pyramidal texture was first obtained at the front surface as described elsewhere [15]. Subsequently, the wafers were cleaned in a complete RCA treatment followed by a final dip in diluted HF (5\%) to etch the oxide grown on the wafer surface. Immediately afterwards, the samples were introduced into the PECVD system to deposit the PAS/ARC stack on the rear side and the heterojunction emitter on the textured front surface. This emitter consisted in a stack of a very thin $(4 \mathrm{~nm})$ intrinsic buffer of a-SiC $: \mathrm{H}_{\mathrm{x}}$ identical to the PAS layer followed by a highly $\mathrm{n}$-doped a-Si:H layer $(10 \mathrm{~nm})$ [15]. As for the rear passivation stack, these layers were also deposited at a substrate temperature of $300^{\circ} \mathrm{C}$. On top of the heterojunction emitter we deposited an indium tin oxide (ITO) front electrode by RF magnetron sputtering at room temperature. A soft annealing step was done at this point to recover the emitter quality after the sputtering process, as it has been proposed in a previous work [17]. The active area of the fabricated devices $\left(1 \mathrm{~cm}^{2}\right.$ and 4 $\mathrm{cm}^{2}$ ) was patterned by a photolithographic step followed by a wet etching to the ITO layer. The $\mathrm{n}$-doped layer surrounding the different devices was also dry-etched to reduce lateral leakage currents. The front electrode is finished with a thermally evaporated $2 \mu \mathrm{m}$ thick silver grid for a $5 \%$ shadowed area. 


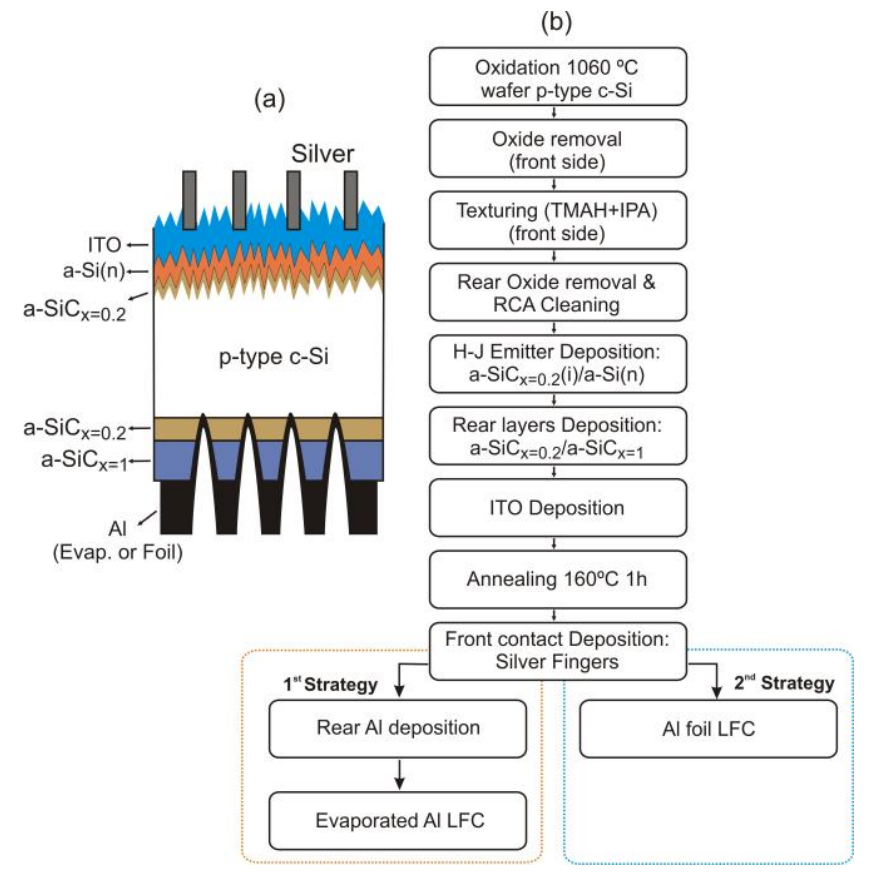

Fig. 2. Structure of the fabricated SHJ solar cells (a) and detailed fabrication process (b) considering the two alternative rear contact strategies studied in this work.

\section{B. Laser-fired contacts}

In reference to the back contact, two different strategies have been studied in this work. The first one, a conventional laser-firing process applied to relatively thin $(2 \mu \mathrm{m})$ thermally evaporated aluminum layers. In the second case, an aluminum foil $(25 \mu \mathrm{m})$ is placed in contact with the passivated surface of the wafer. The formation of air bubbles can be avoided by using a custom chuck and vacuum holding specifically designed for this purpose. In both cases, a q-switched laser beam is used to locally diffuse and alloy aluminum with silicon through the passivation layer. The laser source employed for these experiments was a lamp-pumped Nd:YAG system (StarMarK SMP 100II Rofin-Baassel) operating at $1064 \mathrm{~nm}$ with a pulse duration of $400 \mathrm{~ns}$. The diameter of the laser beam was about $80 \mu \mathrm{m}$ in focus for all the experiments, while the pulse energy was varied between $0.50 \mathrm{~mJ}$ and $0.75 \mathrm{~mJ}$ depending on the contact strategy. A detailed description of the laser-firing process used in this work can be found elsewhere [11][18]. Particularly, it has been shown to enable specific contact resistance values of only $1 \mathrm{~m} \Omega \cdot \mathrm{cm}^{2}$ requiring only 3 laser pulses per contact.

\section{Characterization techniques}

The laser contact morphology was inspected by Scanning Electron Microscopy in a Zeiss Neon 40 workstation. The effective surface recombination velocity $\left(S_{\text {eff }}\right)$ of solar cell precursors, before and after the laser-firing step, was analyzed by the QuasiSteady-State Photoconductance (QSSPC) technique using a Sinton WCT-120 tool. Regarding the electrical characterization of finished devices, the current-voltage characteristics were measured by means of a HP4142B DC source/monitor in dark and also under illumination using a Newport solar simulator. Additionally, External Quantum Efficiency (EQE) curves of the fabricated solar cells were obtained by means of a QEX10 PV Measurements equipment. In order to calculate the Internal Quantum Efficency, the front reflectance spectra of the solar cells were also measured by means of a UV-visible-NIR Shimadzu 3600 spectrophotometer. Finally, Quasi-Steady-State open-circuit voltage $\left(\mathrm{QSSV}_{\mathrm{oc}}\right)$ curves were measured to evaluate the effective lifetime of minority carriers after a complete fabrication process.

\section{RESULTS AND DISCUSSION}

\section{A. Analysis of the Surface Passivation}

The recombination rate $U$ of test samples with a symmetrical passivation on both sides can be expressed as the sum of bulk and surface recombination rates:

$$
U=U_{\text {bulk }}+2 U_{\text {surface }}
$$


this can be rewritten in terms of an effective lifetime $\tau_{\text {eff }}$ :

$$
\frac{\Delta n}{\tau_{e f f}}=\frac{\Delta n}{\tau_{b}}+\frac{2 \mathrm{~S} \Delta n_{s}}{W}
$$

where $\Delta n$ and $\Delta n_{s}$ are the excess densities of minority carriers in the bulk and at the edge of the space charge region close to the surface, respectively, $\tau_{b}$ is the bulk lifetime, $S$ the surface recombination velocity, and $W$ is the thickness of the c-Si wafer. Assuming a nearly flat excess carrier density profile, which is the case for a good surface passivation and long bulk lifetime, it can be considered that $\Delta n$ equals $\Delta n_{s}$ and thus it can be concluded:

$$
\frac{1}{\tau_{e f f}}=\frac{1}{\tau_{b}}+\frac{2 S}{W} \gtrsim \frac{2 S}{W}
$$

and the approximation holds for the high quality FZ c-Si wafers, as used in this study. Consequently, an upper bound of $S$ can be directly calculated from the measured $\tau_{\text {eff }}$ data.
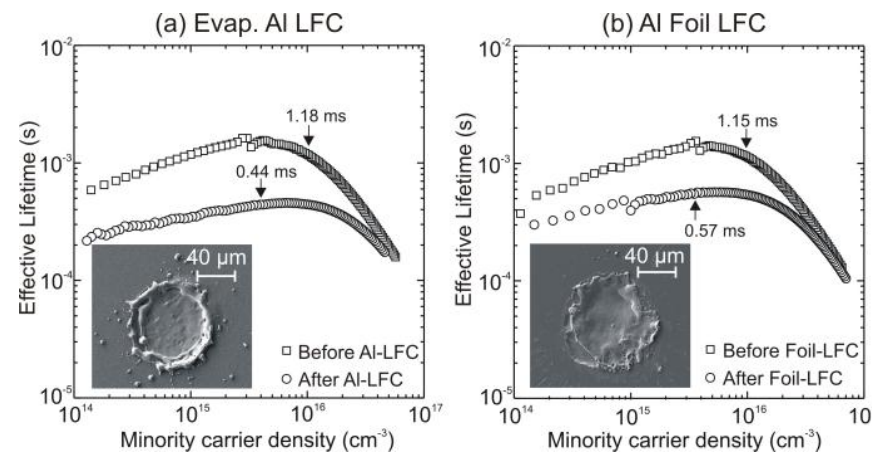

Fig. 3. Effective lifetimes of test structures, before and after the laser-firing process, for evaporated aluminum layers (a) and foils (b). The corresponding $\tau_{\text {eff }}$ values evaluated at one-sun illumination are also pointed out for each curve. The insets show the SEM images of typical LFC contacts obtained in both cases with 3 laser pulses per contact.

The effective lifetimes of symmetrically passivated c-Si wafers $(2.5 \Omega \cdot \mathrm{cm})$ were first measured by QSSPC before the metallization and laser-firing steps. These measurements were used to obtain a direct estimation of the initial surface recombination velocity $\left(S_{\text {initial }}\right)$ by applying equation (3). Then, point contacts were formed by laser-firing either from evaporated aluminum layers or foils on one side of the samples. The distance between the contacts was $1 \mathrm{~mm}$, which results in a contacted area fraction around $0.5 \%$ for the typical radius of the laser-fired contacts being $40 \mu \mathrm{m}$ (at it can be seen in the insets of Fig. 3 ). At this point the aluminum layers and foils were chemically etched or mechanically detached, respectively, to measure again the effective lifetimes. The QSSPC measurements evidenced a significant reduction of about a $60 \%$ in the effective lifetime at onesun irradiance for conventional aluminum laser-fired contacts, while this percentage was around $50 \%$ when using aluminum foils (Fig. 3). Assuming that any degradation in the measured effective lifetime could be attributed to a higher surface recombination velocity at the laser-treated surface $\left(S_{\text {eff,final }}\right)$, equation (3) can be approximated by:

$$
\frac{1}{\tau_{e f f}} \gtrsim \frac{S_{\text {initial }}}{W}+\frac{S_{\text {eff,final }}}{W}
$$

where it has been assumed that $S_{\text {eff,final }}$ was still low enough to assume a nearly flat excess carrier density [14]. Then, equation (4) can be used to estimate the final effective surface recombination velocity at the laser-treated surface:

$$
S_{\text {eff,final }} \lesssim \frac{W}{\tau_{\text {eff }}}-S_{\text {initial }}
$$


These results are compared in Table I for the two different laser-firing strategies under investigation. The $S_{\text {eff.final }}$ values are still rather low after the laser treatment, which supports the assumptions made in equation (4). Nevertheless, the surface recombination velocity is evidently increased in both cases but a slightly lower value is preserved for aluminum foils. Our experimental work has evidenced a good reproducibility of these results, which is especially remarkable for the rather thick ( 25 $\mu \mathrm{m}) \mathrm{Al}$ foil electrode.

\begin{tabular}{ccccc}
\multicolumn{5}{c}{ TABLE I } \\
\hline \hline Laser Treatment & $\begin{array}{r}\text { initial } \\
\tau_{\text {eff }}(\mathrm{ms})\end{array}$ & $\begin{array}{r}\text { final } \\
\tau_{\text {eff }}(\mathrm{ms})\end{array}$ & $\begin{array}{r}S_{\text {initial }} \\
(\mathrm{cm} / \mathrm{s})\end{array}$ & $\begin{array}{c}S_{\text {efffinal }} \\
(\mathrm{cm} / \mathrm{s})\end{array}$ \\
\hline Evap. Al LFC & 1.18 & 0.44 & 10.5 & 61.9 \\
Al Foil LFC & 1.15 & 0.57 & 10.8 & 47.2 \\
\hline \hline
\end{tabular}

Surface recombination velocities at an injection level of one-sun before and after the LFC treatments on symmetrically passivated $2.5 \Omega \cdot \mathrm{cm}$ wafers (test samples).

\section{B. Performance of Heterojunction Solar Cells}

After studying in detail these two alternative laser-firing processes, silicon heterojunction solar cells were fabricated on 0.5 $\Omega \cdot \mathrm{cm}$ and $2.5 \Omega \cdot \mathrm{cm}$ substrates following the procedure shown in Fig. 2. The electrical J-V characteristics were measured in the dark and under standard AM1.5 $\left(100 \mathrm{~mW} / \mathrm{cm}^{2}\right)$ illumination conditions. The photovoltaic performance of the fabricated solar cells is summarized in Table II, which compares the two laser-firing strategies for both wafer resistivities.

TABLE II

\begin{tabular}{ccccc}
\hline \hline Resistivity $(\Omega \cdot \mathrm{cm})$ & \multicolumn{2}{c}{2.5} & \multicolumn{2}{c}{0.5} \\
\hline \hline Laser contact strategy & Al Foil & Evap. Al & Al Foil & Evap. Al \\
\hline \hline$J_{\text {Sc }\left(\mathrm{mA} / \mathrm{cm}^{2}\right)}$ & 35.9 & 34.7 & 34.2 & 33.4 \\
$\operatorname{Voc}(\mathrm{V})$ & 0.644 & 0.645 & 0.690 & 0.688 \\
$F F(\%)$ & 73.7 & 72.8 & 76.5 & 77.4 \\
Efficiency & 17.04 & 16.29 & 18.05 & 17.79 \\
\hline \hline
\end{tabular}

Parameters of the J-V characteristics measured under standard AM1.5 illumination conditions for the best SHJ solar cells fabricated in this work.

The best heterojunction solar cells were those fabricated on $0.5 \Omega \cdot \mathrm{cm}$ substrates, owing to the higher open-circuit voltage and fill factor of these devices. In particular, the highest efficiency of $18 \%$ was obtained for the laser-firing strategy based on aluminum foils. It is remarkable the $\mathrm{V}_{\mathrm{oc}}$ of $690 \mathrm{mV}$, which is close to the highest values reported for double heterojunction structures on ptype c-Si substrates [1][4]. Assuming that the open-circuit voltage gives a good indication of the surface passivation quality, no significant differences were observed between both laser-firing strategies. However, the short-circuit current density seems to be enhanced by the use of aluminum foils. This effect could be related to a better back reflection at the rear electrode, a possibility that will be further discussed in the next section.

\section{Detailed Analysis of Al Foil Electrodes}

The external quantum efficiency (EQE) curves of the fabricated solar cells were also measured to get a deeper insight into the two different laser-firing strategies. Figure 4 compares these curves for the heterojunction solar cells fabricated on $2.5 \Omega \cdot \mathrm{cm}$ wafers. Although one could think that the higher infrared response for the Al foil electrode could be explained by a lower rear surface recombination velocity, this is in contrast to the very similar open-circuit voltage of these devices. In our opinion, the main reason for the enhanced infrared response is actually a higher internal reflection at the rear surface. This possibility seems to be confirmed by the clearly higher reflectance spectra in this region when using an aluminum foil rear electrode. Since the reflectance spectra were measured from the front side, only photons reflected at the rear surface of very weakly absorbed wavelengths could be detected. The absorption of back-reflected photons of energy slightly above the band gap would increase during the additional pass through the whole wafer thickness. A plausible explanation of the improved internal reflectance when aluminum foils are used as a rear contact was given by Nekarda et al. [12]. According to their work, a thin layer of embedded air remaining between the foil and the passivation layer can lead to a better back reflectance in the infrared region. This effect also agrees with the slightly higher short-circuit current densities measured in the solar cells fabricated with a rear aluminum foil electrode. The convolution of the EQE curves with the AM1.5 spectrum over the whole wavelength range can be used to calculate the expected $J_{s c}$ values of the solar cells. According to this the calculated $J_{s c}$ values are $35.7 \mathrm{~mA} / \mathrm{cm}^{2}$ and $34.9 \mathrm{~mA} / \mathrm{cm}^{2}$ 
for the foil and evaporated $\mathrm{Al}$ layer, respectively. Considering experimental uncertainties, these results are in accordance with the values measured under AM1.5 illumination (Table II).

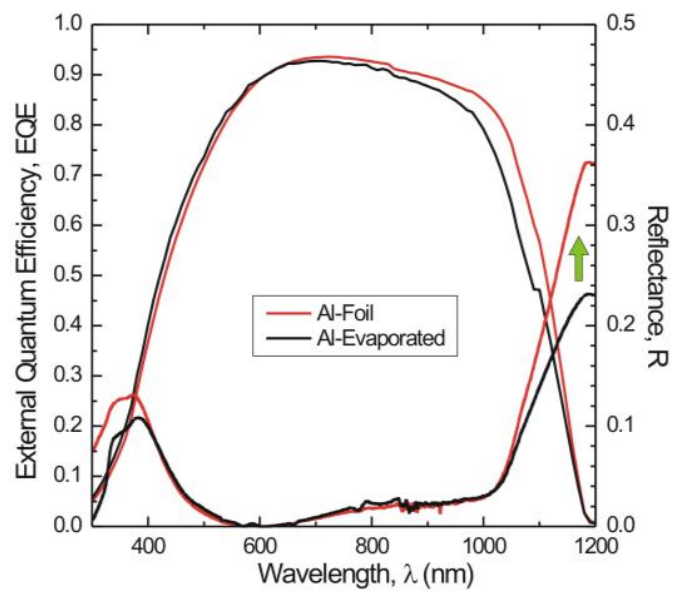

Fig. 4. External quantum efficiency (EQE) curves and reflectance (R) spectra of SHJ solar cells fabricated on $2.5 \Omega \cdot \mathrm{cm}$ substrates with different rear electrodes. A similar behavior was observed for $0.5 \Omega \cdot \mathrm{cm}$ wafers.

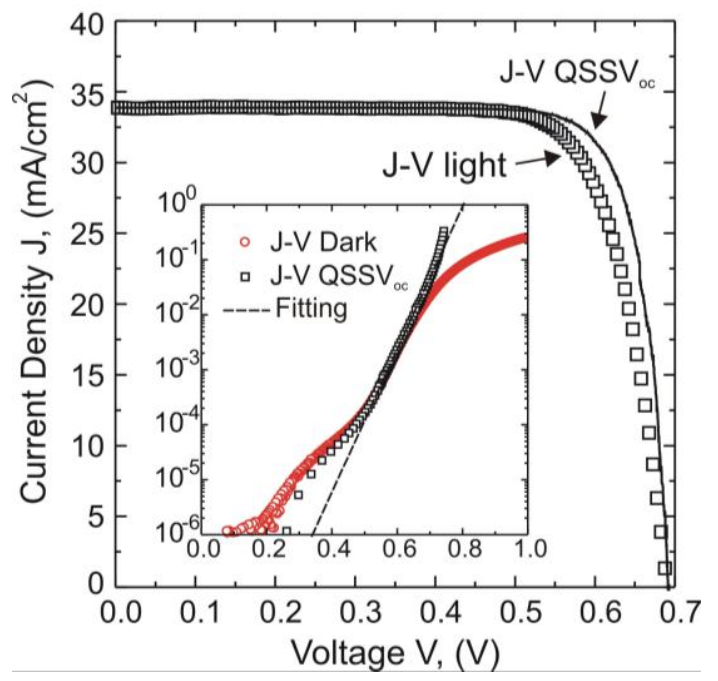

Fig. 5. J-V curve measured under standard AM1.5 illumination conditions compared to the pseudo J-V curve obtained by QSSV $_{\text {oc }}$ for the SHJ solar cell $(0.5 \Omega \cdot \mathrm{cm})$ with an $\mathrm{Al}$ foil electrode. The inset compares the dark $\mathrm{J}-\mathrm{V}$ curve of the same device with its corresponding pseudo J-V curve. The high injection region of the pseudo $\mathrm{J}-\mathrm{V}$ curve is fitted by a single-diode model.

The fabricated solar cells were also characterized by measuring their corresponding Quasi-Steady-State open-circuit voltage $\left(\mathrm{QSSV}_{\mathrm{oc}}\right)$ curves. This technique allows comparing the actual electrical characteristics of the fabricated solar cells to pseudo J-V curves where the effect of the series resistance has been eliminated. Figure 5 compares these curves for a solar cell fabricated with a rear aluminum foil electrode on a $0.5 \Omega \cdot \mathrm{cm}$ substrate. The exponential region of the dark pseudo J-V curve (inset of Fig. 5) could be fitted by considering a single-diode model with a rather low saturation current density $\left(J_{o}=39.5 \mathrm{pA} / \mathrm{cm}^{2}\right)$ and reasonably good ideality factor $(n=1.31)$. The related pseudo fill-factor (pFF) of $81.2 \%$ also reflects the high potential of heterojunction devices with an aluminum foil rear electrode. These measurements were also compared with a conventional laserfiring process and repeated for $2.5 \Omega \cdot \mathrm{cm}$ substrates (Table III). These results evidence that both rear contact strategies can lead to good quality devices, considering the similar pFF values obtained in every case. The parameters of the single-diode model that fitted the dark pseudo J-V curves were also rather similar for each wafer resistivity, independently of the rear contact approach. In addition, the values of the total series resistance $\left(R_{s}\right)$ were calculated for each device from the pFF values deduced from $\mathrm{QSSV}_{\mathrm{oc}}$ data and the parameters of the J-V curve under illumination [19]:

$$
R_{s}=\frac{V_{o c}}{J_{s c}}\left(1-\frac{F F}{p F F}\right)
$$


Similar $R_{S}$ values were obtained by the two laser-firing strategies for a given wafer resistivity (Table III), which indicates their likewise convenience to produce good quality rear electrodes. The $R_{S}$ values of the solar cells fabricated on $2.5 \Omega \cdot \mathrm{cm}$ substrates were higher than those obtained for a lower resistivity of $0.5 \Omega \cdot \mathrm{cm}$. This behavior indicates that the total $R_{S}$ value is finally dominated by the contribution of the base contact. This result explains the lower FF of the solar cells fabricated on $2.5 \Omega \cdot \mathrm{cm}$ substrates (Table II), while their comparably high pFF values (Table III) confirm the good quality of these heterojunction structures.

\begin{tabular}{cccccc}
\multicolumn{6}{c}{ TABLE III } \\
\hline \hline $\begin{array}{c}\text { Resistivity } \\
(\Omega \cdot \mathrm{cm})\end{array}$ & $\begin{array}{c}\text { LFC } \\
\text { strategy }\end{array}$ & $\begin{array}{c}\mathrm{J}_{\mathrm{o}} \\
\left(\mathrm{pA} / \mathrm{cm}^{2}\right)\end{array}$ & $\mathrm{n}$ & $\begin{array}{c}\mathrm{pFF} \\
(\%)\end{array}$ & $\begin{array}{c}\mathrm{R}_{\mathrm{s}} \\
\left(\Omega \cdot \mathrm{cm}^{2}\right)\end{array}$ \\
\hline \hline \multirow{2}{*}{2.5} & Al Foil & 16.9 & 1.18 & 82.4 & 1.89 \\
& Evap. Al & 28.5 & 1.21 & 82.1 & 2.10 \\
\hline \multirow{2}{*}{0.5} & Al Foil & 39.5 & 1.31 & 81.2 & 1.17 \\
& Evap. Al & 38.7 & 1.31 & 81.5 & 1.04 \\
\hline \hline
\end{tabular}

Fitting parameters extracted from the pseudo J-V curves obtained by the $\mathrm{QSSV}_{\text {oc }}$ technique on SHJ solar cells finished with the two different LFC strategies.
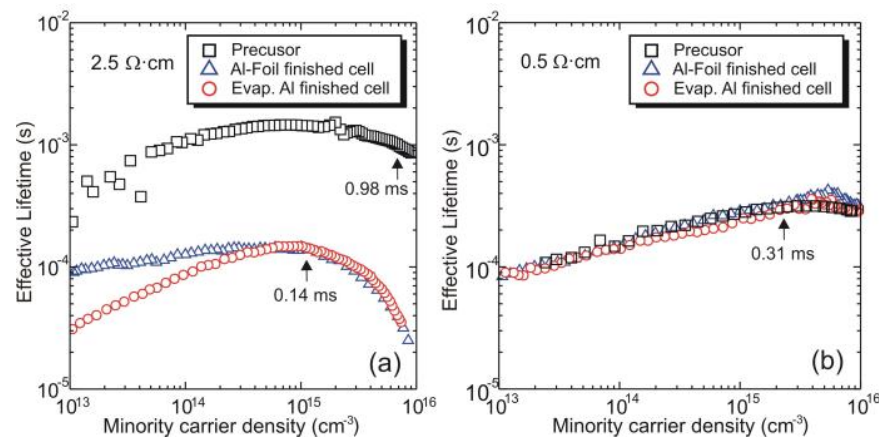

Fig. 6. Effective lifetime vs. excess density of minority carriers for the device precursor (measured by QSSPC) and solar cells (measured by $\mathrm{QSSV}_{\text {oc }}$ ) completed by the two different LFC strategies on (a) 2.5 and (b) $0.5 \Omega \cdot \mathrm{cm}$ substrates. The arrows point to the values at an injection level equivalent to one-sun.

On the other hand, QSSV $_{\mathrm{oc}}$ data can be also used to determine the effective lifetime of minority carriers after a complete fabrication process. This method is based on the following estimation of the effective lifetime [20]:

$$
\tau_{e f f} \approx \frac{\Delta n}{G_{n e t}}
$$

where the net generation rate $G_{n e t}$ is assumed to be uniform, and $\Delta n$ is in this case the average excess of minority carriers. In high-efficiency solar cells with a good surface passivation, the average $\Delta n$ can be approximated by the excess density of minority carriers at the edge of the space charge region. This value can be calculated from the measured open-circuit voltage by taking into account the following relationship [20]:

$$
n p \approx \Delta n\left(N_{A}+\Delta n\right)=n_{i}^{2} \exp \left(\frac{q V_{o c}}{k T}\right)
$$

that can be solved for $\Delta n$ leading to:

$$
\Delta n=\frac{\sqrt{N_{A}^{2}+4 n_{i}^{2} \exp \frac{q V o c}{k T}}-N_{A}}{2}
$$

The net generation rate $G_{n e t}$ can be calculated as [20]:

$$
G_{n e t}=\frac{\left.I_{n e t} f_{a b s} N_{p h}\right|_{1 s u n}}{W}
$$


where $I_{n e t}$ is the illumination intensity measured in suns, $\left.N_{p h}\right|_{\text {ssun }}$ the density of photons with energy higher than the band gap of silicon for an irradiance of one sun, and $f_{a b s}$ the fraction of them effectively absorbed within the c-Si wafer. The value of $I_{n e t}$ is measured by means of a calibrated photodetector installed in the $\mathrm{QSSV}_{\text {oc }}$ set-up, whereas the value of the product $\left.f_{\text {abs }} N_{\text {ph }}\right|_{\text {Isun }}$ can be closely approximated by $J_{s c} / q$. Once the values of $G_{n e t}$ and $\Delta n$ are known, the effective lifetime can be finally estimated by using the equation (7). Figure 6 compares the initial effective lifetimes of solar cell precursors measured by QSSPC to those extracted from $\mathrm{QSSV}_{\text {oc }}$ data for complete devices. Firstly, it is important to note that clear differences were observed between the two wafer resistivities used in this study. In the case of $2.5 \Omega \cdot \mathrm{cm}$ wafers, both types of laser-fired contacts resulted in effective lifetimes significantly reduced with respect to the solar cell precursor. The final $\tau_{\text {eff }}$ values of complete solar cells were very similar at irradiance levels commonly used for device operation, but some increase could be observed at low injection levels in the case of aluminum foil electrodes. This result agrees with the previous characterization of symmetrically passivated test samples (Fig. 3), though slightly lower $\tau_{\text {eff }}$ values were obtained on complete devices. This small reduction could be related to the influence of the heterojunction emitter at the front surface. Note also that the rear electrodes, either an evaporated Al layer or a foil, were removed for the initial QSSPC characterization. Thus, the lower $\tau_{\text {eff }}$ values obtained by QSSV $_{\text {oc }}$ could be also due to a significant loss of field-effect passivation on the rear surface induced by the aluminum electrodes [21]. This effect would be less significant for the $\mathrm{Al}$ foil electrode, since it is not in intimate contact with the rear surface except for a small fraction of contacted area. Concerning the solar cells fabricated on $0.5 \Omega \cdot \mathrm{cm}$ wafers, no significant differences could be resolved by comparing the effective lifetimes of the solar cell precursor and complete devices. These results point to a solar cell performance actually limited by the quality of the front side heterojunction emitter. Anyhow, the low rear surface recombination velocities achieved by either of the laser-firing strategies were sufficient to achieve remarkable open-circuit voltages $(690 \mathrm{mV})$ and conversion efficiencies close to $18 \%$.

\section{CONCLUSIONS}

In this work, a laser-firing approach to create point contacts on SHJ solar cells directly from aluminum foils is compared to the conventional process where a layer is first deposited on the rear passivation stack. This alternative is technologically interesting, as it eliminates the vacuum step required to deposit the aluminum layer by evaporation or sputtering. It has been shown that an adequate optimization leads to a rather low effective surface recombination velocity $\left(S_{\text {eff }}<50 \mathrm{~cm} / \mathrm{s}\right)$ for typical fractions of contacted area $(0.5 \%)$. The series resistance of the solar cells fabricated with an $\mathrm{Al}$ foil rear electrode was very similar to that obtained for standard laser-fired contacts from evaporated Al layers. Therefore, in terms of contact resistance and surface passivation, rear electrodes based on aluminum foils are at least comparable to conventional laser-fired contacts. Furthermore, external quantum efficiency curves and reflectance spectra point to an improved internal reflection for the infrared radiation at the rear surface. Therefore, the solar cells fabricated with rear aluminum foil electrodes presented slightly higher short-circuit current densities. This effect seems to be related to a thin gap of air embedded between the aluminum foil and the rear surface [12]. Thus, the operation of this structure as a back reflector is expected to be superior to that achieved with screen-printed aluminum layers. The best silicon heterojunction solar cells presented in this study were fabricated with an aluminum foil rear electrode, reaching a best conversion efficiency of $18 \%$ with a remarkable open-circuit voltage of $690 \mathrm{mV}$. This result could be already limited by the quality of the heterojunction emitter and front electrode.

\section{REFERENCES}

[1] S. De Wolf, A. Descoeudres, Z. C. Holman, and C. Ballif, "High-efficiency Silicon Heterojunction Solar Cells: A Review", Green, vol. 2, pp. 1-18, Jan. 2012.

[2] M. Taguchi, A. Yano, S. Tohoda, K. Matsuyama, Y. Nakamura, T. Nishiwaki, K. Fujita, and E. Maruyama, "24.7\% Record Efficiency HIT Solar Cell on Thin Silicon Wafer", IEEE J. Photovoltaics, vol. 4, no. 1, pp. 96-99, Jan. 2014.

[3] L. Korte and M. Schmidt, "Doping type and thickness dependence of band offsets at the amorphous/crystalline silicon heterojunction", J. Appl. Phys., vol. 109, no. 6, p. 063714, Mar. 2011.

[4] A. Descoeudres, Z. C. Holman, L. Barraud, S. Morel, S. De Wolf, and C. Ballif, " $>21 \%$ Efficient Silicon Heterojunction Solar Cells on n- and p-Type Wafers Compared", IEEE J. Photovoltaics, vol. 3, no. 1, pp. 83-89, Jan. 2013.

[5] A. W. Blakers, A. Wang, A. M. Milne, J. Zhao, and M. A. Green, "22.8\% efficient silicon solar cell", Appl. Phys. Lett., vol. 55, no. 13, p. 1363 , Sep. 1989.

[6] T. Dullweber, H. Hannebauer, U. Baumann, T. Falcon, K. Bothe, S. Steckemetz, and R. Brendel, "Fine-line printed 5 busbar perc solar cells with conversion efficiencies beyond 21\%”, vol. 1, pp. 621-626, 2014

[7] E. Schneiderlöchner, R. Preu, R. Lüdemann, and S. W. Glunz, "Laser-fired rear contacts for crystalline silicon solar cells", Prog. Photovoltaics Res. Appl., vol. 10, no. 1, pp. 29-34, Jan. 2002.

[8] P. Ortega, A. Orpella, I. Martín, M. Colina, G. López, C. Voz, M. I. Sánchez, C. Molpeceres, and R. Alcubilla, "Laser-fired contact optimization in c-Si solar cells", Prog. Photovoltaics Res. Appl., vol. 20, no. 2, pp. 173-180, Mar. 2012.

[9] P. Engelhart, D. Manger, B. Klöter, S. Hermann, A. . Stekolnikov, S. Peters, H.-C. Ploigt, A. Eifler, C. Klenke, A. Mohr, G. Zimmermann, B. Barkenfelt, K. Suva, J. Wendt, T. Kadent, S. Rupp, D. Rychtarik, M. Fischer, J. . Müller, and P. Waver, "Q.ANTUM - Q-Cells next generation high-power silicon cell \& module concept", 26th Eur. Photovolt. Sol. Energy Conf. Exhib., pp. 821-826, 2011.

[10] I. Sánchez-Aniorte, R. Barrio, A. Casado, M. Morales, J. Cárabe, J. J. Gandía, and C. Molpeceres, "Optimization of laser-firing processes for siliconheterojunction solar-cell back contacts", Appl. Surf. Sci., vol. 258, no. 23, pp. 9443-9446, Sep. 2012.

[11] C. Molpeceres, M. Colina, D. Muñoz-Martin, I. Martín, P. Ortega, I. Sánchez, M. B. Morales, S. Lauzurica, J. J. García-Ballesteros, C. Voz, G. López, A.B. Morales, and R. Alcubilla, "New laser-based approaches to improve the passivation and rear contact quality in high efficiency crystalline silicon solar cells", in SPIE Solar Energy + Technology, 2013, p. 882603.

[12] J. Nekarda, M. Graf, A. Rodofili, A. Wolf, and R. Preu, "Laser-based foil rear side metallization for crystalline silicon solar cells", Proc. SPIE, vol. 8473, p. 847307 , Oct. 2012. 
[13] W. Brendle, V. X. Nguyen, A. Grohe, E. Schneiderlöchner, U. Rau, G. Palfinger, and J. H. Werner, "20·5\% Efficient Silicon Solar Cell With a Low Temperature Rear Side Process Using Laser-Fired Contacts", Prog. Photovoltaics Res. Appl., vol. 14, no. 7, pp. 653-662, Nov. 2006.

[14] P. Ortega, I. Martín, G. Lopez, M. Colina, A. Orpella, C. Voz, and R. Alcubilla, "p-type c-Si solar cells based on rear side laser processing of Al2O3/SiCx stacks", Sol. Energy Mater. Sol. Cells, vol. 106, pp. 80-83, Nov. 2012.

[15] A. Morales, C. Voz, M. Colina, G. López, I. Martín, A. Orpella, J. Puigdollers, M. García, and R. Alcubilla, "Progress in Silicon Heterojunction Solar Cell fabrication with rear laser-fired contacts", IEE Explor., vol. 120000, pp. 345-348, 2012.

[16] J. Nekarda, A. Grohe, O. Schultz, and R. Preu, "Aluminum foil as back side metallization for LFC cells", Proc. 22nd EU PVSEC, pp. 1499-1501, 2007.

[17] A. Morales-Vilches, C. Voz, M. Colina, G. López, I. Martín, P. Ortega, A. Orpella, and R. Alcubilla, "Recovery of Indium-tin-oxide/silicon Heterojunction Solar Cells by Thermal Annealing”, Energy Procedia, vol. 44, pp. 3-9, 2014.

[18] M. Colina, I. Martín, C. Voz, A. Morales-Vilches, P. Ortega, G. López, A. Orpella, M. García-Molina, D. Muñoz-Martín, M. I. Sánchez-Aniorte, C. Molpeceres, and R. Alcubilla, "Optimization of Laser Processes for Local Rear Contacting of Passivated Silicon Solar Cells", Energy Procedia, vol. 44, pp. 234-243, 2014.

[19] A.L. Fahrenbruch and R.H. Bube, New York: Academic. 1983, pp. 220-222.

[20] M. J. Kerr, A. Cuevas, and R. a. Sinton, "Generalized analysis of quasi-steady-state and transient decay open circuit voltage measurements", J. Appl. Phys., vol. 91, no. 1, p. 399, 2002.

[21] C. Leendertz, N. Mingirulli, T. F. Schulze, J. P. Kleider, B. Rech, and L. Korte, "Discerning passivation mechanisms at a-Si:H/c-Si interfaces by means of photoconductance measurements", Appl. Phys. Lett., vol. 98, no. 20, p. 202108, May 2011. 